\section{Commentary: A conceptual roadmap to spinal cord protection in thoracoabdominal aortic surgery}

\author{
Carlo Rosati, MD, and Gabriele Di Luozzo, MD
}

Performing a thoracoabdominal aortic aneurysm (TAAA) repair is somewhat like replacing the main fuel line of a car engine while the car is running. Spinal cord ischemia is among the most devastating complications that can occur, but fortunately, its incidence can be reduced by the use of various adjuncts. Many authors have focused on the physiology of the spinal cord vascular supply and blood flow, vascular anatomy, and plasticity of the arterioles in the vascular network to understand how adjuncts and different approaches can ameliorate spinal ischemia. ${ }^{1-3}$

In this review by the aortic surgery team of the University of Colorado, the authors provide a useful framework of the main points to consider to prevent such a complication or to rescue the patient from it should one occur. ${ }^{4}$

This article is a valuable and succinct bullet point index of what to think about when addressing the spinal cord protection in TAAA repair. The authors provide a list of the concepts that an aortic surgeon should keep in mind when performing the most central and complex "plumbing" operation in the human body.

Over the last 2 decades or so, we have developed an approach to TAAA repairs that seems to provide a very low risk of spinal cord ischemia. ${ }^{5}$ We focus on 4 main concepts: hypothermia, maintenance of spinal cord perfusion pressure, staging of repairs, and neuromonitoring. ${ }^{1-3,6,7}$ The authors, much like other surgical groups, have

From the Icahn School of Medicine at Mount Sinai, New York, NY.

Disclosures: The authors reported no conflicts of interest.

The Journal policy requires editors and reviewers to disclose conflicts of interest and to decline handling or reviewing manuscripts for which they may have a conflict of interest. The editors and reviewers of this article have no conflicts of interest

Received for publication Feb 3, 2021; revisions received Feb 3, 2021; accepted for publication Feb 4, 2021; available ahead of print Feb 8, 2021.

Address for reprints: Gabriele Di Luozzo, MD, Icahn School of Medicine at Mount Sinai, 440 West 114th St, Pavilion Second Floor, New York, NY 10025 (E-mail: gabriele.diluozzo@mountsinai.org).

JTCVS Techniques 2021;8:18-9

2666-2507

Copyright (c) 2021 The Authors. Published by Elsevier Inc. on behalf of The American Association for Thoracic Surgery. This is an open access article under the CC BY-NCND license (http://creativecommons.org/licenses/by-nc-nd/4.0/).

https://doi.org/10.1016/j.xjtc.2021.02.013

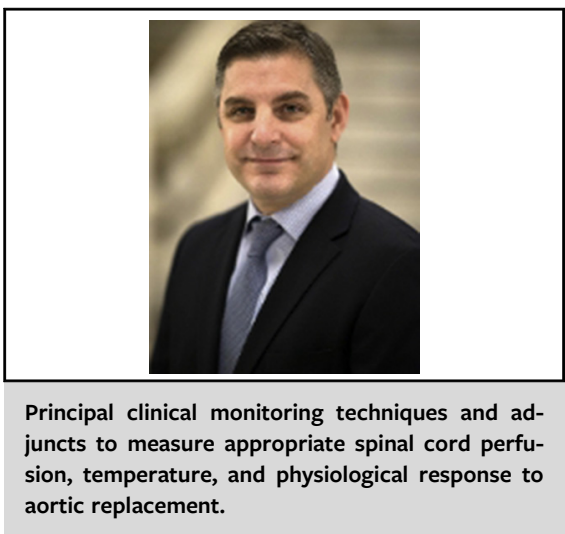

CENTRAL MESSAGE

Understanding the (patho)physiologic elements of spinal cord perfusion and metabolism and how we can intervene on them is key to preserving neurologic function intraoperatively and postoperatively.

developed an approach to spinal cord preservation. Although we can argue about the nadir of the temperature for organ preservation and the utility of spinal artery reimplantation, ultimately, a well-coordinated plan is vital to neuroprotection. ${ }^{5-7}$ Hypothermia $\left(31^{\circ} \mathrm{C}-33^{\circ} \mathrm{C}\right)$ has a clear benefit in neuroprotection; however, some authors have proposed deep hypothermia as their method of choice. We have elected to avoid spinal artery reimplantation in clinical practice, although we focus a great deal on maintaining spinal cord perfusion through extrasegmental arteries, lowering cerebrospinal fluid pressure, maintaining persistent hypothermia in the early postoperative period, and augmenting mean arterial pressure. These adjuncts and techniques have been developed and maintained in our clinical practice and have resulted in acceptable neurologic outcomes.

Much like the authors, we continue to study this area of aortic surgery with an aspiration of eliminating this deadly complication. We congratulate the authors on their previous studies and organization of ideas on this important topic that continues to intrigue many aortic surgeons.

\section{References}

1. Etz CD, Kari FA, Mueller CS, Silovitz D, Brenner RM, Lin HM, et al. The collateral network concept: a reassessment of the anatomy of spinal cord perfusion. J Thorac Cardiovasc Surg. 2011;141:1020-8. 
2. Weiss AJ, Pawale A, Griepp RB, Di Luozzo G. Deep versus mild hypothermia during thoracoabdominal aortic surgery. Ann Cardiothorac Surg. 2012;1:329-33.

3. Geisbüsch S, Schray D, Bischoff MS, Lin HM, Griepp RB, Di Luozzo G. Imaging of vascular remodeling after simulated thoracoabdominal aneurysm repair. J Thorac Cardiovasc Surg. 2012;144:1471-8.

4. Kemp CM, Feng Z, Aftab M, Reece TB. Preventing spinal cord injury following thoracoabdominal aortic aneurysm repair: the battle to eliminate paraplegia. $J$ Thorac Cardiovasc Surg Tech. 2021;8:11-5.
5. Etz CD, Halstead JC, Spielvogel D, Shahani R, Lazala R, Homann TM, et al Thoracic and thoracoabdominal aneurysm repair: is reimplantation of spinal cord arteries a waste of time? Ann Thorac Surg. 2006;82:1670-7.

6. Di Luozzo G, Wilderman M, Pawale A, McCullough J, Griepp RB. Planned staged repair of thoracoabdominal aortic aneurysms to minimize spinal cord injury: a proof of concept. Aorta (Stamford). 2015;3:177-80.

7. Etz CD, Zoli S, Bischoff MS, Bodian C, Di Luozzo G, Griepp RB. Measuring the collateral network pressure to minimize paraplegia risk in thoracoabdominal aneurysm resection. J Thorac Cardiovasc Surg. 2010;140(6 Suppl):S125-30; discussion S142-6. 